\title{
Blood flow pattern in the ascending aorta after TAVI and conventional aortic valve replacement: Analysis using 4D-Flow MRI
}

\author{
Ralf F Trauzeddel ${ }^{3 *}$, Ulrike Loebe ${ }^{1}$, Alex J Barker ${ }^{2}$, Carmen Gelsinger ${ }^{1}$, Christian Butter ${ }^{1}$, Michael Markl ${ }^{2}$, \\ Jeanette Schulz-Menger ${ }^{3}$, Florian von Knobelsdorff-Brenkenhoff ${ }^{3}$
}

From 18th Annual SCMR Scientific Sessions

Nice, France. 4-7 February 2015

\section{Background}

Transarterial aortic valve implantation (TAVI) is a valid alternative to treat aortic stenosis in patients with high surgical risk. The impact of TAVI on changes in blood flow dynamics in the ascending aorta has not been systematically analyzed. Using temporally resolved, three-dimensional, phase contrast MRI (4D-flow), we studied 3D hemodynamics in the ascending aorta (AAo) after TAVI and compared the results to patients with conventional aortic valve replacement (AVR) as well as healthy controls.

\section{Methods}

We enrolled 17 subjects with TAVI (Edwards Sapien, mean age $77 \pm 7$ years, 9 males), 12 with biological AVR
( $77 \pm 4$ years, 8 males), and 9 healthy subjects $(55 \pm 16$ years, 8 males). All underwent $4 \mathrm{D}$-flow MRI at $1.5 \mathrm{~T}$ (spatial resolution $1.8 \times 1.8 \times 2.5 \mathrm{~mm}^{3}$, temporal resolution $40.8 \mathrm{~ms}$ ). Analysis included quantification of the regional distribution of peak systolic wall shear stress (WSS) and peak systolic flow velocity in the AAo.

\section{Results}

The mean aortic orifice area was $1.9 \pm 0.2 \mathrm{~cm}^{2}$ (TAVI), $1.4 \pm 0.4 \mathrm{~cm}^{2}$ (AVR) and $4.0 \pm 0.8 \mathrm{~cm}^{2}$ (Controls) $(\mathrm{p}<0.001)$. Mean aortic diameter was $35 \pm 3 \mathrm{~mm}, 39 \pm 4 \mathrm{~mm}$ and $31 \pm 5 \mathrm{~mm}(\mathrm{p}=0.002)$. Patients with TAVI and AVR showed an asymmetric distribution of systolic WSS in the AAo compared to controls. WSS was significantly

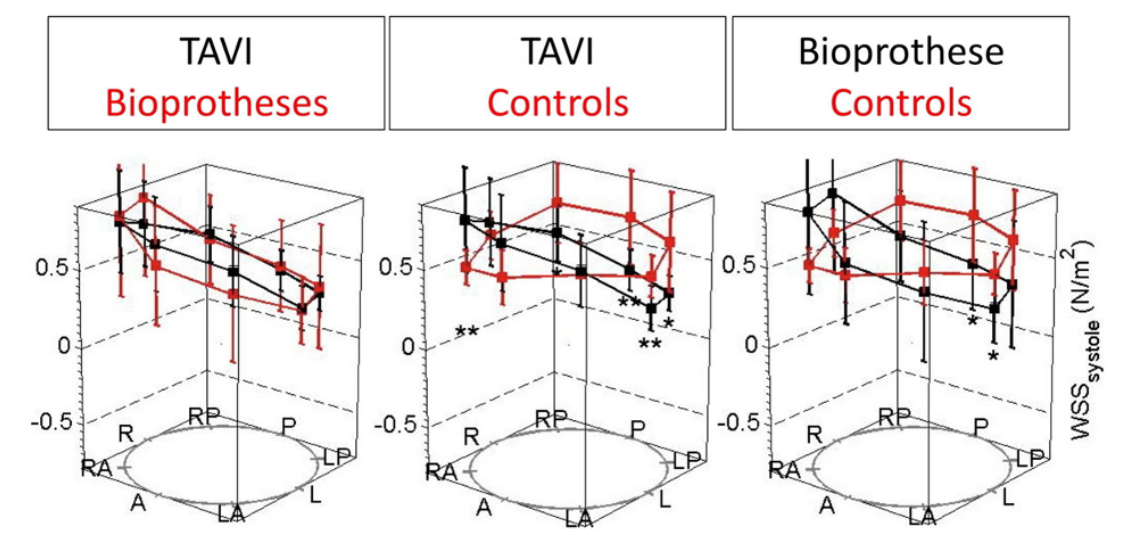

Figure 1 Distribution of wall shear stress in the ascending aorta ( $a=a$ anterior, $p=$ posterior, l=left, $r=r i g h t)$.

${ }^{3}$ Cardiology, ECRC, Charité University Medicine Berlin and HELIOS Clinics,

Berlin, Germany

Full list of author information is available at the end of the article

(c) 2015 Trauzeddel et al; licensee BioMed Central Ltd. This is an Open Access article distributed under the terms of the Creative Commons Attribution License (http://creativecommons.org/licenses/by/4.0), which permits unrestricted use, distribution, and reproduction in any medium, provided the original work is properly cited. The Creative Commons Public Domain Dedication waiver 

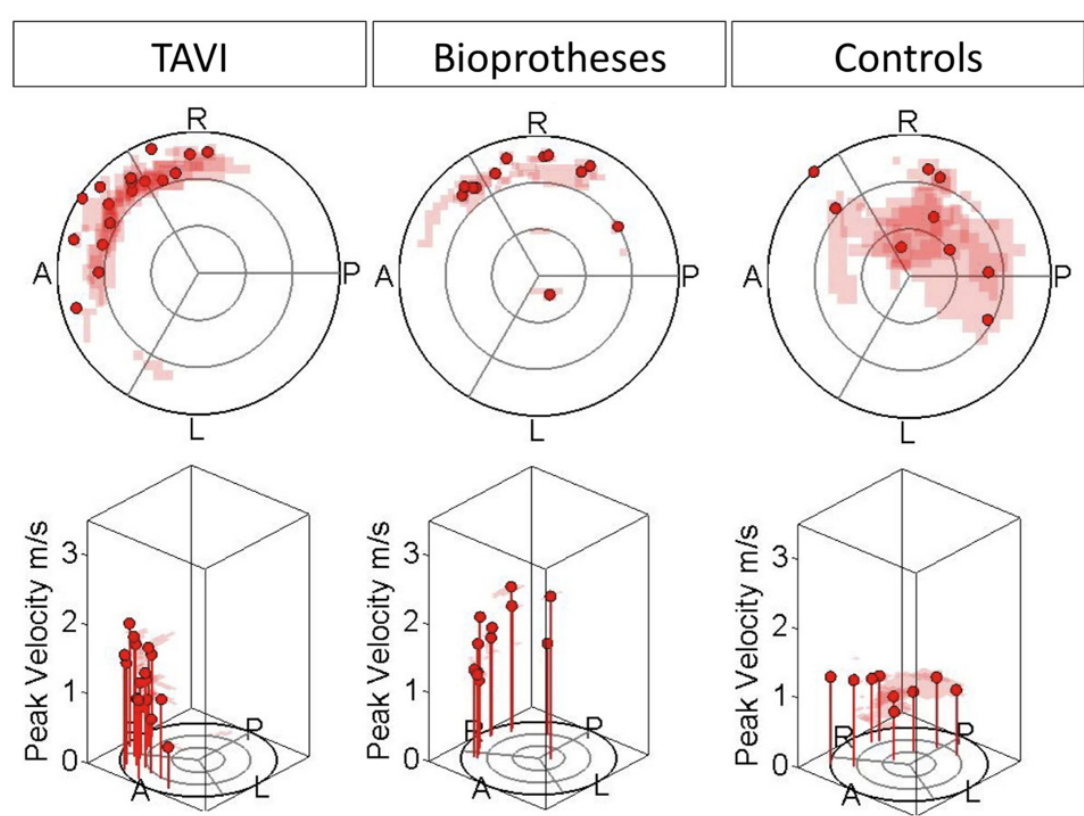

Figure 2 Distribution of peak blood flow velocity in the ascending aorta ( $a=$ anterior, $p=$ posterior, $l=l e f t, r=r i g h t)$.

elevated anteriorly and right-anteriorly, and reduced posteriorly (Fig. 1). WSS distribution was similar in TAVI and AVR. Both TAVI and AVR exhibited the peak flow velocity along the right-anterior curvature, while this was more central in controls (Fig. 2). Peak velocities did not differ between TAVI and AVR $(\mathrm{p}=0.550)$.

\section{Conclusions}

TAVI and AVR lead to similar alterations in systolic blood flow patterns in the ascending aorta compared to healthy controls.

\section{Funding}

None.

\section{Authors' details}

${ }^{1}$ Cardiology, Heart Center Brandenburg, Bernau, Germany. ${ }^{2}$ Radiology,

Northwestern University, Chicago, IL, USA. ${ }^{3}$ Cardiology, ECRC, Charité

University Medicine Berlin and HELIOS Clinics, Berlin, Germany.

Published: 3 February 2015

doi:10.1186/1532-429X-17-S1-068

Cite this article as: Trauzeddel et al:: Blood flow pattern in the ascending aorta after TAVI and conventional aortic valve replacement: Analysis using 4D-Flow MRI. Journal of Cardiovascular Magnetic Resonance 2015 17(Suppl 1):O68.
Submit your next manuscript to BioMed Central and take full advantage of:

- Convenient online submission

- Thorough peer review

- No space constraints or color figure charges

- Immediate publication on acceptance

- Inclusion in PubMed, CAS, Scopus and Google Scholar

- Research which is freely available for redistribution 